\title{
Libras ABC: aplicativo para auxílio de aprendizagem da Língua Brasileira de Sinais
}

\author{
Heloneida Camila Costa Coelho ${ }^{1}$, Olavo Nylander Brito Neto ${ }^{1}$ \\ ${ }^{1}$ Instituto Federal de Educação,Ciência e Tecnologia do Amapá (IFAP) - 68.090-398 - \\ Macapá, AP - Brasil \\ (heloneidacamila@gmail.com, Olavo.brito@ifap.edu.br)
}

\begin{abstract}
Educational applications can stimulate student interest and contribute to the teaching-learning method. It is known that students use electronic devices a lot, and that they can be used to good pedagogical practices. This paper presents the development of an educational application for teaching Brazilian Sign Language (Libras), for Android, as a way to encourage the use of technology in education. The adopted methodology involved a brief bibliographical study about the theme and the development of a mobile app prototype. The result turned out to be plausible by demonstrating that application use can contribute to the educational system.
\end{abstract}

RESUMO: Os aplicativos educacionais podem estimular o interesse do aluno e contribuir no método de ensino aprendizagem. Sabe-se que os alunos utilizam constantemente dispositivos eletrônicos, e que estes podem ser utilizados às boas práticas pedagógicas. Este artigo apresenta o desenvolvimento de um aplicativo educacional para o ensino da Língua Brasileira de Sinais (Libras), para Android, como forma de incentivar o uso de tecnologia na educação. A metodologia adotada envolveu um breve estudo bibliográfico acerca do tema e o desenvolvimento de um protótipo de aplicativo para dispositivo móvel. O resultado se mostrou plausível, por demonstrar que a utilização de aplicativo pode contribuir com o sistema educacional.

\section{Introdução}

Considerando relatos e dados que a inclusão escolar é uma realidade, este é o momento de aceitar e fazer valer essa prática, através de atitudes viáveis e responsabilidade com o processo inclusivo. Pois para que haja inclusão do aluno surdo, são necessárias algumas mudanças no contexto escolar, na prática do professor, e na aceitação dos demais alunos, porque a aprendizagem do surdo é diferente do aluno ouvinte, principalmente aos assuntos relacionados a escrita e interpretação de textos. De acordo com dados do MEC (BRASIL, 2014), a maioria das crianças surdas chegam à escola sem nenhum conhecimento em língua de sinais e seus familiares também desconhecem tal língua, isso dificulta a aprendizagem desse aluno.

A proposta da pesquisa tem por objetivo principal trabalhar a inclusão do aluno surdo, através do uso de um aplicativo educacional para auxiliar o ensino da língua brasileira de sinais na escola, além de melhorar e facilitar a compreensão com base no alfabeto em Libras. Pode ser considerado que essa pesquisa é de abordagem qualitativa, descritiva, que tem por objetivo mostrar os dados pesquisados, através, do contato do 
pesquisador e o objeto pesquisado, pois ambos possuem uma relação indissociável, no que diz respeito aos fenômenos e todo processo que envolve o resultado da pesquisa. (MINAYO, 2013).

Justifica-se esse estudo devido ao fato das modificações sofridas pela sociedade no decorrer do tempo, dentre elas o desenvolvimento tecnológico e o aprimoramento de novas maneiras de pensamento sobre o saber e sobre o processo pedagógico, têm refletido principalmente nas ações dos alunos no contexto escolar. A geração atual estudantil já tem contato com as inovações tecnológicas constantemente fora do ambiente escolar, e o acesso à informação se dá instantaneamente.

O artigo é dividido além desta seção introdutória em mais seis seções, sendo que a segunda descreve o cenário de uso, a terceira trata do desenvolvimento do aplicativo quanto às ferramentas utilizadas para isto, na quarta seção está a apresentação do aplicativo, voltada para explicar a funcionalidade do mesmo, a quinta consiste na análise dos resultados dessa pesquisa, já a sexta traz as considerações acerca do estudo e finaliza com referencias bibliográficas utilizadas durante este processo teórico.

\section{Cenário de uso}

O protótipo de aplicativo LibrasABC foi desenvolvido como ferramenta de uso educacional, possui como característica principal apresentar uma proposta de acesso livre e gratuita, aliada ao uso de tecnologia, neste caso, desenvolvida como apoio pedagógico para o ensino da Língua Brasileira de Sinais (Libras) no Ensino Fundamental. Serão apresentadas as ferramentas e linguagens de programação utilizadas em sua construção e ainda as possibilidades oferecidas pelo aplicativo para a aprendizagem móvel.

Para MANTOAN (2006) a meta da inclusão desde o início, é não deixar ninguém fora do sistema escolar, onde as instituições deverão adaptar-se as particularidades de todos os alunos. Com isso surge o ambiente especializado de atendimento (AEE), este espaço visa manter a escola acessível, tanto no contexto da inclusão do aluno em salas regulares, como também nos processos interdisciplinares e sociais da escola. Esse desafio deve perpassar os muros da instituição e avançar no ensino aprendizagem, para tal, é necessário compreender o processo dessa educação, estudar formas que possam inserir o aluno com deficiência nas esferas educacionais, com formação de profissionais para assistência dessa modalidade dentro da escola.

Com base nos dados da pesquisa realizada por SANTANA (2019), pode-se perceber que certos problemas da educação são comuns em outros lugares do Brasil, a falta de infraestrutura escolar, que não é adequada, o próprio acesso a ferramentas tecnológicas, ainda é escasso, além da falta de capacitação profissional, mesmo com os avanços de incentivo a formação continuada no Brasil, a demanda ainda é grande e a disponibilidade não atende ou não consegue suprir essa carência. Sendo assim, esta pesquisa vem salientar a importância do uso de novas técnicas pelos profissionais de ensino, incentivando a utilização de práticas atrativas como forma de criar ambientes diferentes do tradicional, visando a melhoria da aprendizagem, principalmente no ensino.

Para PASSINI (2018) atualmente existe uma relação entre cultura digital e educação inovadora, onde temos uma reflexão sobre os usos e opções de tecnologias 
midiáticas para serem trabalhadas na educação, sendo assim, os profissionais que devem se atualizar e verificar a melhor maneira de aliar a tecnologia ao ensino. A proposta deste aplicativo é incentivar os alunos quanto a importância da escrita correta, como meio de ampliar seu conhecimento, além de facilitar sua comunicação e formar a base para o próprio processo de aprendizagem, através de uma competição entre ele mesmo e o software.

Sabe-se que o ensino da língua Portuguesa já é uma tarefa árdua para os docentes, imagina então introduzir o ensino de Libras, é a escola, portanto, o espaço linguístico fundamental, pois normalmente é o primeiro local que o aluno surdo entra em contato com a língua brasileira de sinais. Por meio da língua de sinais, ele vai adquirir a linguagem. Como diz KARNOPP (2004), as pessoas não constroem significados em vácuo. Isso significa que ela estará concebendo um mundo novo usando uma língua que é percebida e significada ao longo do seu processo. Todo esse processo possibilita a significação por meio da escrita que pode ser na própria língua de sinais, bem como, no português.

De acordo com o MEC (BRASIL, 2014) esses alunos deveriam ter na escola o auxílio do Intérprete Tradutor de Língua de Sinais, porém essa ainda não é uma prática comum no ensino público. Este profissional poderia ser a ponte para a comunicação entre os alunos surdos e os ouvintes, mediando o entendimento e a compreensão dos conteúdos trabalhados na série em que frequentam.

A escolha desse tema está relacionada aos interesses educacionais, e também como forma de disseminar o conhecimento acerca de recursos disponíveis dentro do contexto tecnológico e do ensino das Libras. Segundo BASSO (2009) o ensino de Libras estão ligados à praticas pedagógicas, onde é preciso considerar tanto os fatores internos quanto externos que levam a esse conhecimento. Onde os Fatores Internos, estão relacionados ao próprio processo de aprendizagem do aluno, e os externos são os fatores relacionados a questões sociais e históricas sobre.

O público alvo desse estudo são os alunos surdos que ainda estão desenvolvendo as habilidades com a linguagem de sinais, mas isso não exclui os alunos ouvintes. Com o reconhecimento e a regulamentação da Libras, o ensino inclusivo tomou por base a visão sociológica de deficiência e diferença, reconhecendo que todas as pessoas são diferentes, e que as escolas como as universidade precisam ser transformadas para atender às necessidades individuais de todos os educandos - com ou sem necessidade especial. A Libras, como qualquer outra língua, tem sua estrutura gramatical com os seus níveis linguístico-semânticos e se diferencia das outras por ser visual-espacial, é esta acepção que chega ao ensino.

\section{Desenvolvimento}

A primeira etapa de qualquer aplicativo é saber o objetivo e o público alvo, ou seja, a ideia que vai movê-lo ou o problema que será resolvido por ele. O desenvolvimento do LibrasABC iniciou após um breve estudo bibliográfico, para embasar as informações básicas do aplicativo educacional. Devido ao rápido processo de evolução tecnológica dos últimos anos, se tornou imprescindível aliar à tecnologia a educação tentando manter um equilíbrio entre as duas, sabe-se que esse processo exige do professor, uma nova maneira de agir e pensar na educação. É importante que os profissionais reflitam 
sobre a influência constante e crescente que a informática tem em nossas vidas. Com base em estudos realizados dentro da temática de informática Educativa, Coelho (2019), afirma ser viável o uso de aplicativos, de acordo com seu estudo realizado usando o protótipo Brincando com Palavras, a tecnologia funcionou muito bem, aliada ao ensino, e a aceitação dos alunos foi perceptível com base nos dados apresentados.

Para dar encaminhamento na produção do Libras $A B C$ foi necessário fazer um levantamento de requisitos básicos para seu funcionamento: Quantidade de telas do aplicativo; Cores e organização, além dos botões de cada tela; as imagens que serão utilizadas; e o desenvolvimento do layout geral do aplicativo. Como descritos, os requisitos elencados foram as propriedades básicas para iniciar o projeto e são considerados indispensáveis para que o aplicativo funcione correto e seja satisfatório para utilização do docente em sala de aula.

Após definir os requisitos básicos do LibrasABC, montou-se então um wireframe, neste caso, com as sugestões de possíveis telas do aplicativo. Com base no conceito de VAN DIJCK (2006), que diz que os wireframes são esboços da interface que o usuário terá contato, indicando como funcionarão links, botões funcionais e outros elementos que possam influenciar o uso da interface e a relação entre eles. Sendo assim, nesta fase foi definido o layout de cada botão e alinhamento das telas, já verificando a simetria dos ícones, dimensões e a qualidade de navegabilidade por meio do usuário.

Para desenvolver este aplicativo, foi utilizada a plataforma virtual App Inventor, que se mostrou viável, por ser uma ferramenta fácil de manusear, e por ser uma plataforma gratuita, de código aberto, disponível via web, facilitando o acesso. Ele permite que programadores leigos desenvolvam aplicativos para o sistema operacional Android, de forma simples e rápida, pois trabalha com programação em blocos, transformando assim o desenvolvimento do aplicativo mais prático e rápido.

Reconhecendo esse potencial em massa dos dispositivos móveis, e associando isto à prática do ensino, surgem diariamente diversos aplicativos educacionais. Sendo assim, para desenvolver o Libras $A B C$ foi necessário investigar a existência de outros aplicativos semelhantes, assim, pode-se realizar um comparativo de conteúdo com os jogos ForcaBRAS, Alfabeto Libras, Alfabeto KidsLibras, esses jogos têm características similares ao Libras $A B C$, o foco deles é trabalhar Libras com ludicidade, seus layout é simples e atrativo, essas ferramentas também são utilizadas em dispositivos móveis, e trabalham com textos e sinais, relacionados ao alfabeto em Libras. Vale ressaltar que eles são gratuitos e podem ser baixados em lojas virtuais para aplicativos móveis.

O diferencial nesse caso do Libras $A B C$, é principalmente o layout e a disposição do alfabeto do teclado no modelo $Q W E R T$, fazendo o usuário trabalhar a Libras por associação, para os que já conhecem e utilizam esse tipo de teclado, algo que ainda é pouco explorado nesse contexto de aplicativos.

\section{Apresentação do software}

O Libras $A B C$ vem explorar a competência linguística dos alunos na língua de sinais, é uma língua detentora de características próprias e reconhecida em todos os aspectos linguísticos, como morfologia, sintaxe e pragmática, a Libras se diferencia do português na medida em que se apresenta na modalidade visuoespacial, ou seja, composta por um conjunto de movimentos e expressões captados pela visão. Assim o aplicativo serve 
para que busquem sempre o aprimoramento de suas habilidades dentro da língua de sinais.

A proposta do aplicativo é ser utilizada prioritariamente com alunos de ensino fundamental, por isso, pensou-se em telas de fácil manuseio, layout simples, mas que fosse atrativa. Este aplicativo foi desenvolvido inicialmente com 10 imagens, e assim trabalhar a grafia dessas palavras, mas a proposta é atualizar o vocabulário frequentemente. O jogo se divide em quatro telas, sendo que na primeira (ver Figura 1), o usuário tem disponível três botões, o botão de "ALFABETO LIBRAS", onde ele é encaminhado para outra tela que mostra o alfabeto em Libras atualizado, e assim servirá de suporte para o aluno tirar dúvidas quanto ao sinal de determinada letra, ou até mesmo aprender o alfabeto, caso ainda tenha dificuldade. Nesta tela o usuário pode usar o botão "VOLTAR", para retornar à tela inicial, ou o botão "INICIAR JOGO" que o encaminha para o jogo. Ainda na tela inicial temos também o botão "SAIR" que fecha aplicação, ou o usuário pode usar o botão "JOGAR”, que irá passar para tela de início de jogo.

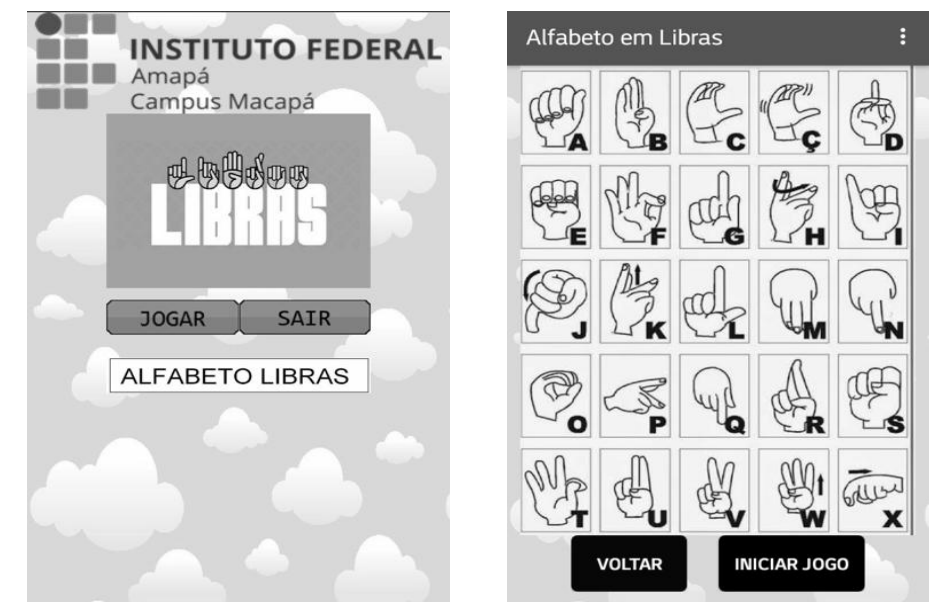

Figura 1 - Telas 1 e 2 do aplicativo LibrasABC.

Na segunda tela, onde o jogo inicia (ver figura 2), temos 4 botões de controle de atividades, que são o de "VOLTAR", "VERIFICAR", "PRÓXIMA" e "ENCERRAR".

1. VOLTAR: O usuário pode retornar a tela inicial do jogo;

2. VERIFICAR: Este botão deve ser clicado para verificar se o usuário acertou a escrita da imagem que aparece na tela;

3. PRÓXIMA: Serve para passar para a próxima imagem, e começar uma nova palavra do aplicativo;

4. ENCERRAR: Encerra a página de jogo e abre a tela "fim".

Todo o layout desta tela foi pensado para manter uma boa "jogabilidade" do usuário, tornando visualmente agradável, entre tons, botões e quantidade de imagens. $\mathrm{O}$ aplicativo possui botões referentes a cada letra do alfabeto da língua portuguesa, porém com a imagem do sinal de Libras. 


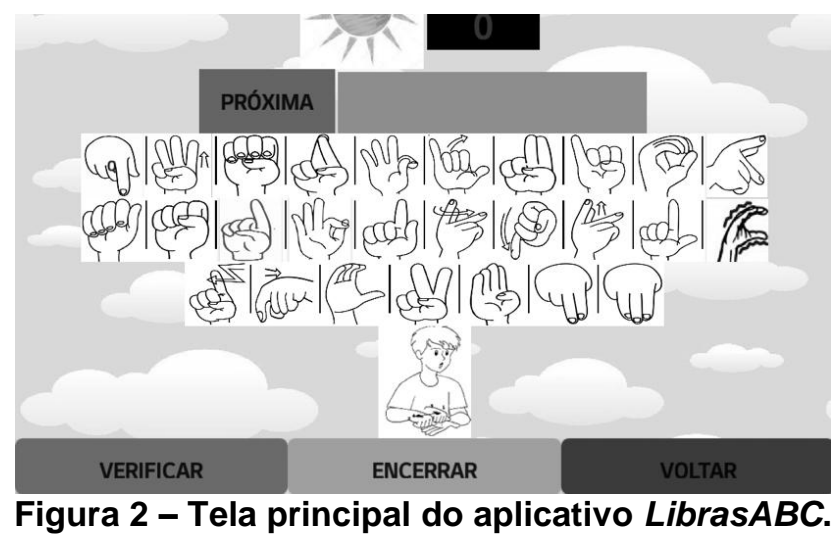

A última tela do jogo (ver Figura 3) é composta por apenas um botão, onde o usuário pode fechar a aplicação. Nesta tela aparece a pontuação final do usuário, com base nos acertos e erros do mesmo.

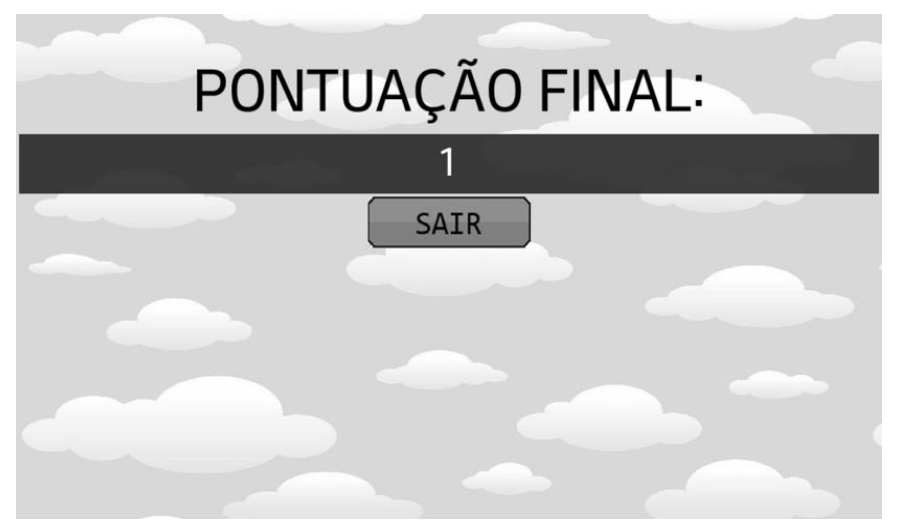

Figura 3 - Tela final do aplicativo Librasabc.

Este aplicativo foi planejado para um melhor desempenho quando utilizado em telas de 7 polegadas, como tablets por exemplo, porém, ele funciona bem em qualquer dispositivo com sistema Android versão 4.0 ou superior. Vale ressaltar que a interface do aplicativo passou por alterações em relação as imagens de fundo e as cores, para melhorar a visibilidade dos elementos gráficos, sem comprometer os elementos de jogo. A ideia é sempre incentivar mais o uso da LIBRAS dentro da escola, principalmente através de atividades diferentes que estimulem os alunos ao aprendizado. O link para acesso ao aplicativo segue disponível no endereço abaixo: $<$ https://drive.google.com/file/d/1mkeIDuAuShLdIA3w3kXC2Cz41p5r9QTb/view? usp $=$ sharing $>$

\section{Análise de resultados}

Os primeiros testes desse protótipo foram realizados com 3 alunos de ensino Fundamental II, de escola pública, com deficiência auditiva, por isto a quantidade amostral é baixa, uma vez que este público faz parte de um grupo pequeno dentro da educação. Os alunos participantes já fazem acompanhamento com os profissionais especializados para atendimento de ensino especial (AEE). Os responsáveis dos alunos foram orientados quanto ao interesse da pesquisa, mediante apresentação de termo de consentimento. 
Para avaliar o protótipo foi necessário usar questionário, para verificar as percepções deles como usuários, relacionando pontos positivos e negativos da plataforma apresentada, como organização e a dinâmica de funcionamento. De acordo com os usuários, o aplicativo como um todo é interessante e fácil de manusear, gostaram do que ele propõe para jogo, além das cores e estrutura, porém solicitaram que fosse ampliado o número de palavras, para tornar o aplicativo mais complexo. Esta ferramenta pode auxiliar a atividade didático-pedagógico das instituições, inserindo todos que fazem parte do cotidiano escolar dos alunos surdos, tendo como referência mostrar a importância de conhecer a língua brasileira de sinais, que é uma forma de incluir esses alunos que se sentem excluídos pelos demais.

Verificamos que todos os participantes alegaram já conhecer Libras, mas com conhecimento razoável, ou seja, ainda estão desenvolvendo e aprendendo a língua de sinais. Dentro desse contexto, ainda responderam no questionário que todos conhecem o alfabeto em Libras. Isso foi um ponto positivo para o uso do aplicativo, pois era importante eles conhecerem as letras para facilitar o acesso deles.

De acordo com os resultados do questionário sobre características do aplicativo Libras $A B C$, percebe-se a boa aceitação da ferramenta. Com base nas respostas dos questionários, foi verificado que os discentes gostaram da ferramenta, salvo algumas críticas, citadas anteriormente, e claro, o interesse deles em utilizar mais recursos tecnológicos na escola, esses tipos de atividades podem contribuir para uma aprendizagem mais satisfatória, e assim facilitar o entendimento sobre os assuntos mais complexos, contribuindo para o processo de ensino-aprendizagem, que irá garantir uma aula dinâmica, e assim trazer mudanças positivas na prática pedagógica.

\section{Considerações}

Os aspectos abordados durante a contextualização deste artigo estão baseados em pesquisas que apontam a importância de aliar tecnologia às práticas de ensino. Apesar de ainda ser um protótipo, percebe-se que o aplicativo tem potencial para ser utilizado em sala, pois esta ferramenta aliou bem, o uso da tecnologia e o ensino, este que é alvo de reclamações constante de alunos, por acharem o ensino monótono, e por falta de interesse dos próprios discentes.

É evidente que o aplicativo desenvolvido nesse estudo ainda precisa ser aprimorado, e a ideia é continuar os estudos e ampliar o leque de usuários envolvidos. Apesar de simples, ele já se mostrou uma boa ferramenta no uso escolar, visando avaliar diretamente a habilidade dos alunos, quanto ao uso da língua de sinais, item este, que é fundamental para o desenvolvimento individual e principal responsável em incluir o aluno surdo ao ambiente escolar.

Assim, diante de que se obteve de informação sobre a temática e a discussão com o os resultados, considera-se que sujeitos surdos e ouvintes podem romper as barreiras da comunicação através da utilização da Libras. Para isso é necessário continuar o estudo, aperfeiçoando erros do aplicativo e ampliar a abrangência de usuários que irão utilizar o mesmo. Será necessário fazer experimentações com mais casos práticos, promover discussões, refinar os conceitos, formalizar notações, etc. Os testes iniciais só foram usados em escolas públicas, mas a ideia é levar também para o ensino particular nos próximos estudos. 
Ao completar esta fase do estudo pode-se afirmar que este aplicativo vem trazer novas perspectivas de ensino, ajudando o aluno a aprender de forma lúdica e atrativa a Língua de sinais, mais precisamente o alfabeto em Libras. Esta pesquisa analisou de fato, um problema presente na educação, e considera-se que o LibrasABC pode ser uma importante ferramenta didática que busca eficiência no processo de ensino aprendizagem dos alunos, desenvolvendo assim uma boa relação entre a prática docente e o uso de tecnologias no ensino. É notório que o celular pode ser um aliado da educação, já que ganhou grande espaço no ambiente escolar, cabe aos profissionais da educação se conectarem a essas novas tendências e buscar conhecer as opções que eles podem utilizar, para aprimorar a qualidade do ensino.

\section{Referências}

BASSO, Idavania Maria de Souza; STROBEL, Karin Lilian, MASUTTI, Mara. Metodologia de Ensino de Libras - L1. Universidade Federal de Santa Catarina Licenciatura em Letras-Libras na Modalidade a Distância. Florianópolis-SC, 2009.

BRASIL. Secretaria de Educação Básica. Diretoria de Apoio à Gestão Educacional. Caderno de educação especial: a alfabetização de crianças com deficiência: uma proposta inclusiva/ Ministério da Educação, Secretaria de Educação Básica, Diretoria de Apoio à Gestão Educacional. - Brasília: MEC, SEB, 2014. 48P.

COELHO, Heloneida; BRITO NETO, Olavo. Desenvolvimento de Aplicativo para Ensino de Língua Portuguesa. Anais do Workshop de Informática na Escola, [S.1.], p. 1164, nov. 2019. ISSN 2316-6541. Disponível em: <https://brie.org/pub/index.php/wie/article/view/8629>. Acesso em: 06 dez. 2019. doi:http://dx.doi.org/10.5753/cbie.wie.2019.1164.

KARNOPP, L. - Língua de Sinais Brasileira: Estudos Linguísticos. PortoAlegre: ArtMed, 2004.

MINAYO, Maria Cecília de Souza et al. Pesquisa social: teoria, método e criatividade. Vozes, 2013.

MANTOAN, Maria Teresa Egler, Rosangela Gavioli Pietro; Valeria Amorim Arantes, Inclusão Escolar: pontos e contrapontos - São Paulo : Summus, 2006. - p.103.

PASSINI, L. H. S. and Campos, G. H. B. (2018). A rota da aprendizagem: seriam os games uma via?. In VII Congresso Brasileiro de Informática na Educação (CBIE 2018), Anais do XXIX Simpósio Brasileiro de Informática na Educação (SBIE 2018). Disponível em: <http://dx.doi.org/10.5753/cbie.sbie.2018.1771>. Acesso em 18 de Setembro de 2019.

SANTANA, Bianca ; ARAÚJO, Luis ; BITTENCOURT, Roberto . Computação e Eu: Uma Proposta de Educação em Computação para o Sexto Ano do Ensino Fundamental II. In: WORKSHOP SOBRE EDUCAÇÃO EM COMPUTAÇÃO (WEI-SBC), 27. , 2019, Belém. Anais do XXVII Workshop sobre Educação em Computação. Porto Alegre: Sociedade Brasileira de Computação, july 2019 . p. 21-30. ISSN 2595-6175.

VAN DIJCK, J. (2006) Picturizingscience: The sciencedocumentary as multimediaspectacle. InternationalJournalof Cultural Studies, vol. 9, n. 5. 